Article

\title{
Response of Water-Salt Migration to Brackish Water Irrigation with Different Irrigation Intervals and Sequences
}

\author{
Jinjin Zhu, Mao Yang, Junna Sun * and Zhenhua Zhang * \\ School of Resources and Environmental Engineering, Ludong University, Yantai 264025, China; \\ jinjin2417@vip.163.com (J.Z.); ym38736102@163.com (M.Y.) \\ * Correspondence: jnsun@yic.ac.cn (J.S.); zhangzh71@163.com (Z.Z.)
}

Received: 18 June 2019; Accepted: 2 October 2019; Published: 7 October 2019

\begin{abstract}
Establishing methods for scientific and rational use of brackish water resources is the key to farmland irrigation in the Yellow River Delta region of China. In this study, we conducted laboratory simulation experiments with soil columns and monitored the changes in water infiltration and salt distribution under eight irrigation treatments, including four intervals $(0,30,60$, and $90 \mathrm{~min}$ between irrigations) and two sequences (brackish-brackish-fresh water and brackish-fresh-brackish water). The results showed that the duration of water infiltration into the soil was higher under intermittent irrigation than continuous irrigation, with the highest value recorded at the 90-min irrigation interval. There was no significant difference in the mean soil water content between the brackish-brackish-fresh water (28.01-29.71\%) and brackish-fresh-brackish water (28.85-29.98\%) irrigation treatments. However, the mean soil desalination rate of the brackish-brackish-fresh irrigation treatment (42.51-46.83\%) was higher than that of the brackish-fresh-brackish irrigation treatment (39.48-46.47\%), and a much higher soil desalination rate was observed at the 90-min irrigation interval, compared with the other intervals. In conclusion, brackish-brackish-fresh water irrigation at longer time intervals (e.g., $90 \mathrm{~min}$ between irrigations) is conducive to reduce soil salt content in the surface soil in the study region.
\end{abstract}

Keywords: alternating irrigation; desalination rate; intermittent irrigation; sodium adsorption ratio; soil water content

\section{Introduction}

There are large reserves of brackish water resources under the ground, which show great application potential for farmland irrigation [1]. Salt leaching, with brackish water, plays a role in reducing soil salt content [2]. However, the $\mathrm{Na}^{+}$in brackish water can change soil physicochemical properties and reduce soil permeability, leading to the formation of soil crust and posing a potential risk of soil salinization [3,4]. How to make scientific and rational use of brackish water resources is the key to farmland irrigation with brackish water in coastal regions.

Brackish water irrigation is often implemented through direct irrigation with brackish water, mixed irrigation with brackish and fresh water, and alternating irrigation with brackish and fresh water [5]. Some researchers [6-8] found that alternating irrigation with brackish and fresh water is a better strategy than mixed irrigation for the improvement of crop yield in India. In addition, other studies showed that improper time intervals between irrigations causes deep percolation of water or increased salt accumulation in the surface soil $[9,10]$. Xue et al. [11]. This recorded higher cumulative infiltration in clay soil after three irrigations with saline water (2-6 g/L salinity) at a 30-min interval, compared with 60- and 90-min intervals. However, only brackish water irrigation was tested in the above study, while fresh water was not included for alternating irrigation. 
In order to save fresh water resources, an increased proportion of brackish water can be used for irrigation, e.g., a 2:1 ratio of brackish to fresh water. For example, Su et al. [12] applied alternating irrigation to a clay loam soil with brackish ( $3 \mathrm{~g} / \mathrm{L}$ salinity) and fresh water $(0.5 \mathrm{~g} / \mathrm{L}$ salinity) in different sequences. They found that two brackish water irrigations did not markedly increase soil salt content compared with one brackish water irrigation, while brackish-fresh-brackish water irrigation was more efficient in soil desalination than fresh-brackish-brackish water irrigation. However, the sequence of alternating irrigation with brackish and fresh water was incomplete in the above study, as it lacked a comparison with brackish-brackish-fresh water irrigation. Studies that combine different sequences and intervals of irrigation, with brackish and fresh, water can provide useful data for the development of rational irrigation strategies.

In the present study, a 2:1 ratio of brackish to fresh water was used for simulated irrigation experiments with a silty loam soil, collected from the Yellow River Delta region in Shandong Province, China. The study region is characterized by low and flat terrain with high groundwater level. This region is irrigated with Yellow River water, poorly drained, and prone to seawater intrusion. These conditions have resulted in a high level of soil salinization, which seriously restricts the economic development at a regional scale $[13,14]$. The aim of this study was to evaluate the effects of different irrigation intervals $(0,30,60$, and $90 \mathrm{~min}$ ) and sequences (brackish-brackish-fresh and brackish-fresh-brackish) on the redistribution of soil water and salt in the Yellow River Delta region. The results provide support for the rational use of brackish water resources for farmland irrigation in the study region.

\section{Materials and Methods}

\subsection{Experimental Soil and Irrigation Water}

The experimental soil was taken from the Coastal Wetland Ecological Experiment Station of Yellow River Delta ( $37^{\circ} 45^{\prime} 50^{\prime \prime}$ N, $118^{\circ} 59^{\prime} 24^{\prime \prime}$ E), Chinese Academy of Sciences. Plants are patchily distributed at the sampling site. The composition of plant communities was simple, mainly comprising salt-tolerant plants. The dominant species were Phragmites australis, Tamarix chinensis, and Imperata cylindrica. In 2017, five soil samples were taken from a depth of 0-30 $\mathrm{cm}$ using a spade. After removing impurities by hand, the soil sample was air-dried and mixed, then passed through a $2 \mathrm{~mm}$ sieve before use. The basic physicochemical properties of the soil sample are shown in Table 1.

Table 1. Basic physicochemical properties of the experimental soil.

\begin{tabular}{|c|c|c|c|c|c|c|c|c|c|c|c|c|}
\hline \multirow{2}{*}{$\begin{array}{c}\text { Soil } \\
\text { Texture }\end{array}$} & \multicolumn{3}{|c|}{$\begin{array}{l}\text { Particle size Composition } \\
(\%)\end{array}$} & \multirow{2}{*}{$\begin{array}{c}\text { Field } \\
\text { Capacity (\%) }\end{array}$} & \multirow{2}{*}{$\begin{array}{c}\text { Initial } \\
\text { Water (\%) }\end{array}$} & \multirow[t]{2}{*}{$\mathrm{pH}$} & \multirow{2}{*}{$\begin{array}{l}\text { Electrical Conductivity } \\
(\mathrm{mS} / \mathrm{cm})\end{array}$} & \multirow{2}{*}{$\begin{array}{c}\text { Total Salt } \\
(\mathrm{g} / \mathrm{kg})\end{array}$} & $\mathrm{Cl}^{-}$ & $\mathrm{Ca}^{2+}$ & $\mathrm{Mg}^{2+}$ & $\mathrm{Na}^{+}$ \\
\hline & Gravel & Silt & Clay & & & & & & \multicolumn{4}{|c|}{$(\mathrm{g} / \mathrm{kg})$} \\
\hline Silty loam & 11.6 & 48.7 & 39.7 & 28.04 & 1.04 & 7.4 & 1.88 & 4.50 & 0.27 & 0.57 & 0.30 & 2.90 \\
\hline
\end{tabular}

Underground brackish water ( $\sim 3 \mathrm{~g} / \mathrm{L}$ salinity) resources, mainly containing $\mathrm{Na}^{+}$and $\mathrm{Cl}^{-}$, are widely distributed in the shallow subsurface of the Yellow River Delta region. To simulate the underground water in this region, brackish water was formulated with $\mathrm{NaCl}$ and distilled water ( $3 \mathrm{~g} / \mathrm{L}$ salinity). Whereas, fresh water was prepared using distilled water $(0 \mathrm{~g} / \mathrm{L})[15,16]$. The irrigation amount was calculated from the field capacity using Equation (1) [17],

$$
M=H \times A\left(\theta_{\max }-\theta_{0}\right) \gamma_{\text {soil }} / \gamma_{\text {water }}
$$

where $M$ is the irrigation amount (i.e., $412 \pm 5 \mathrm{~mL}$ ); $H$ is the depth of the designed soil wetting layer $(\mathrm{cm}) ; A$ is the irrigated area of soil $\left(\mathrm{cm}^{2}\right) ; \theta_{\max }$ is the maximum allowable water content in designed soil wetting layer (\%, on a dry soil basis), generally equal to the field capacity (i.e., $28.04 \%$ ); $\theta_{0}$ is the initial water content in designed soil wetting layer ( $\%$, on a dry soil basis), $\gamma_{\text {soil }}$ is the bulk density of 
soil $\left(\mathrm{g} / \mathrm{cm}^{3}\right)$; and $\gamma_{\text {water }}$ is the density of water $\left(\gamma_{\text {water }}=1.00 \mathrm{~g} / \mathrm{cm}^{3}\right.$ for both brackish water and fresh water based on laboratory measurements).

\subsection{Infiltration Experiments}

The experimental setup consisted of a soil column and a water supply device (Figure 1 ). The soil column ( $46 \mathrm{~cm}$ in total height) was assembled with 23 plexiglass tubes $(6 \mathrm{~cm}$ in inner diameter and $2 \mathrm{~cm}$ in height). The tube was fixed by four screws, with small holes of $2 \mathrm{~mm}$ diameter evenly distributed on the bottom board for ventilation. Vaseline was evenly spread onto the tube wall at joints to minimize the effects of pores on the inner wall of the tube during infiltration. Water was supplied using a Markov bottle with a cross-sectional area of $22.89 \mathrm{~cm}^{2}$ and a height of $60 \mathrm{~cm}$. The outer walls of the soil column and the Markov bottle were marked with scales, in order to monitor the depth of wetting front migration in the soil column and the water level in the Markov bottle.

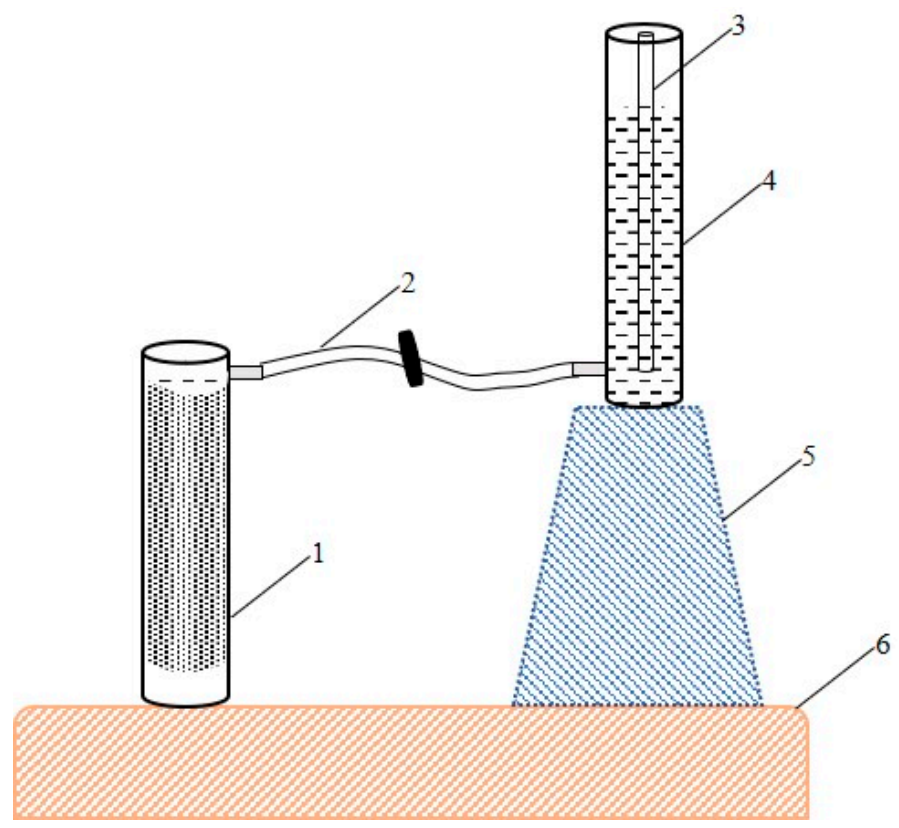

Figure 1. Experimental setup for one-dimension vertical water infiltration. (1) Soil column; (2) Water pipe; (3) Intake tube; (4) Markov bottle; (5) Retort stand; and (6) Desktop.

Before the start of the experiment, two layers of quartz sand were filled at the bottom for ventilation. Next, soil was filled into the column by layers ( $2 \mathrm{~cm}$ each layer) to give the bulk density of $1.35 \mathrm{~g} / \mathrm{L}$ and a total height of $40 \mathrm{~cm}$. The soil surface was covered with a filter paper to prevent scouring of the soil during irrigation. The soil column was allowed to sit for $12 \mathrm{~h}$ before experimentation. The water head was controlled at $1-2 \mathrm{~cm}$ and time was recorded using a stopwatch. Changes in the depth of wetting front and the water level in the Markov bottle were recorded at different time intervals from dense to sparse.

Eight irrigation treatments were applied, including four intervals $(0,30,60$, and $90 \mathrm{~min}$ between irrigations) and two sequences (brackish-fresh-brackish water (BFB); and brackish-brackish-fresh water (BBF)). Each treatment had three replicates. For each irrigation cycle, an equal volume (137 $\pm 1 \mathrm{~mL})$ of irrigation water (brackish or fresh) was applied three times in the indicated sequence with a specific time interval between irrigations. For example, for the BFB treatment at the 90-min irrigation interval, $137 \pm 1 \mathrm{~mL}$ of brackish water was first applied; then, $137 \pm 1 \mathrm{~mL}$ of fresh water was applied $90 \mathrm{~min}$ after the infiltration of brackish water was completed; subsequently, $137 \pm 1 \mathrm{~mL}$ of brackish water was applied again $90 \mathrm{~min}$ after the infiltration of fresh water was completed.

Due to the stable supply of water, the water potential gradient at the wetting front was generally large. Thus, when the irrigation was completed, the migration and redistribution of soil water were 
driven continuously by the large water potential gradient. A study observed relatively stable soil water content in a silty loam soil $20 \mathrm{~h}$ after the end of water infiltration [18]. Therefore, after irrigation treatment, the soil column was allowed to stand for $20 \mathrm{~h}$ before sampling. Soil samples were taken from different depths at $4 \mathrm{~cm}$ intervals. The content of soil water after redistribution was measured by oven drying method $\left(40{ }^{\circ} \mathrm{C}, 10 \mathrm{~h}\right)$. The electrical conductivity in soil extract (water: soil $=5: 1, \mathrm{v} / \mathrm{v}$ ) was measured using a digital conductivity meter (DDS11A, Yoke, Shanghai, China) and then converted to soil salt content. Soil $\mathrm{Na}^{+}$content was measured by atomic absorption spectrophotometer, while soil $\mathrm{Ca}^{2+}$ content and $\mathrm{Mg}^{2+}$ content were measured by EDTA titration.

\section{Data Analysis}

The cumulative infiltration refers to the total amount of water infiltrated into the soil per unit surface area [19]. Here the cumulative infiltration was calculated using Equation (2):

$$
I=h \times 0.81
$$

where $I$ is the cumulative infiltration $(\mathrm{cm}) ; h$ is the cumulative decrease of the water level in the Markov bottle $(\mathrm{cm})$; and 0.81 is the ratio of the cross-sectional area of the Markov bottle to the soil column used in the experiment.

After the end of water infiltration, the distribution of soil water determines the extent of water adsorption and utilization by the crops and the availability of soil water to the crops. Soil water content was calculated using Equation (3) [20]:

$$
\theta_{m}=100 \% \times m_{w} / m_{s}
$$

where $\theta_{m}$ is the soil water content (\%); $m_{w}$ is the mass of water contained in soil (g); and $m_{s}$ is the mass of dry soil (g).

Soil salt content was calculated using Equation (4):

$$
\text { Soil salt content }(\mathrm{g} / \mathrm{kg})=1.857 \times E C_{5: 1}+1.011
$$

where $E C_{5: 1}$ is the electrical conductivity in soil extract with a 5:1 ratio of water to soil at $24.5^{\circ} \mathrm{C}$ $(\mathrm{mS} / \mathrm{cm})$.

A higher soil desalination rate indicates a better salt leaching effect by water, which is beneficial for the improvement of saline-alkali soil. Soil desalination rate was calculated using Equation (5) [21]:

$$
\text { Soil desalination rate }(\%)=100 \% \times(S 1-S 2) / S 1
$$

where $S 1$ is the initial salt content in the soil $(S 1=4.50 \mathrm{~g} / \mathrm{kg}$; Table 1) and $S 2$ is the salt content at specific soil depths after redistribution $(\mathrm{g} / \mathrm{kg})$.

A higher soil sodium adsorption ratio (SAR) poses a greater risk to soil. The SAR was calculated according to Equation (6) [22]:

$$
S A R=\frac{\left[\mathrm{Na}^{+}\right]}{\sqrt{\frac{1}{2}\left(\left[\mathrm{Ca}^{2+}\right]+\left[\mathrm{Mg}^{2+}\right]\right)}}
$$

where $\left[\mathrm{Na}^{+}\right],\left[\mathrm{Ca}^{2+}\right]$, and $\left[\mathrm{Mg}^{2+}\right]$ are expressed in $\mathrm{mmol} / \mathrm{L}$.

Statistical analysis was conducted using SPSS Statistics 19.0 for Windows (IBM SPSS, Somers, USA). The analysis of variance (ANOVA) for a randomized block design was performed in order to evaluate the significance of irrigation sequence and interval on the duration of water infiltration, soil water content, desalination rate, and soil sodium adsorption ratio (Table 2). The data were checked for the normality of the distribution using Shapiro-Wilk test and for homogeneity of variance using 
Levene's test. The means were examined by a one-way ANOVA, followed by a post hoc test (e.g., Duncan or Tukey).

Table 2. Mean water content (\%) in the silty loam at depths of $0-32 \mathrm{~cm}$ under different irrigation treatments (BBF, brackish-brackish-fresh water; $\mathrm{BFB}$, brackish-fresh-brackish water).

\begin{tabular}{ccccc}
\hline \multirow{2}{*}{ Treatment } & \multicolumn{4}{c}{ Irrigation Interval (min) } \\
\cline { 2 - 5 } & $\mathbf{0}$ & $\mathbf{3 0}$ & $\mathbf{6 0}$ & $\mathbf{9 0}$ \\
\hline BBF & $28.01 \pm 0.33 \mathrm{a}$ & $29.24 \pm 0.60 \mathrm{a}$ & $28.47 \pm 0.39 \mathrm{a}$ & $29.71 \pm 0.33 \mathrm{a}$ \\
BFB & $28.85 \pm 0.75 \mathrm{a}$ & $29.66 \pm 0.29 \mathrm{a}$ & $29.36 \pm 0.92 \mathrm{a}$ & $29.98 \pm 0.48 \mathrm{a}$ \\
\hline
\end{tabular}

Note: Different letters indicate significant differences $(P<0.05)$. Here, no significant difference was found.

\section{Results}

\subsection{Effects of Irrigation with Brackish and Fresh Water on Water Infiltration}

The cumulative infiltration of water in the silty loam increased as a function of time, but the magnitude of increase gradually declined with different irrigation treatments. Within the same period of time, the cumulative infiltration decreased with increasing irrigation interval. For example, within the first 330 min of BFB treatment, the cumulative infiltration reached $14.01 \mathrm{~cm}$ at the 0 -min irrigation interval. As the irrigation interval increased to 30,60, and $90 \mathrm{~min}$, the cumulative infiltration decreased by $20.14 \%, 31.39 \%$, and $50.43 \%(P<0.05)$, respectively. Concerning the irrigation sequence, the BBF treatment increased the cumulative infiltration, compared with the BFB treatment at each irrigation interval. For example, with irrigation applied at a 60-min interval, the cumulative infiltration of BBF treatment was $10.94 \mathrm{~cm}$, which was $10.17 \%$ higher than that of BFB treatment $(P<0.05$; Figure 2$)$.
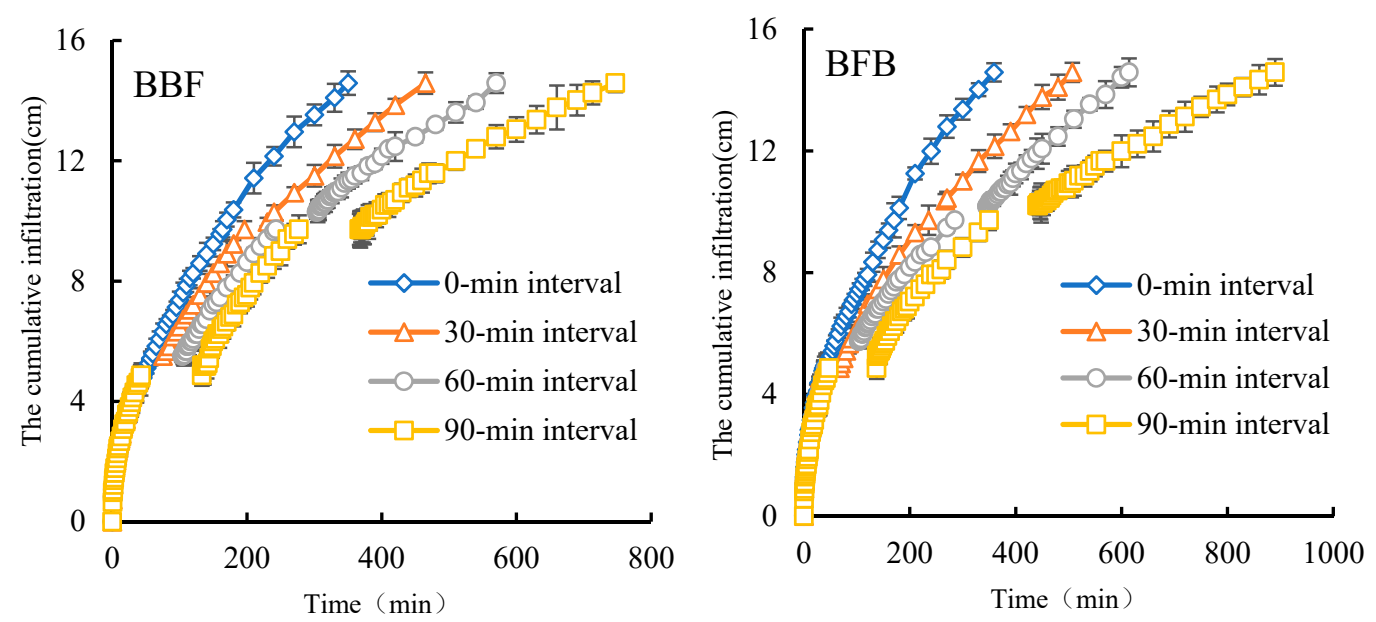

Figure 2. Changes in cumulative infiltration of water in the silty loam under different irrigation treatments (BBF, brackish-brackish-fresh water; BFB, brackish-fresh-brackish water).

Unlike the cumulative infiltration, the duration of water infiltration under different treatments significantly increased with increasing irrigation interval $(P<0.05)$. Specifically, the infiltration of water lasted 359 min under the BFB treatment at the 0-min interval. Whereas, an increase in the irrigation interval, from 0 to $90 \mathrm{~min}$, resulted in a $97.77 \%$ increase in the duration of infiltration. Comparing different irrigation sequences revealed that the BBF treatment shortened the duration of infiltration compared with the BFB treatment. Especially at the 90-min irrigation interval, the BBF treatment resulted in 567 min of infiltration, which was $25.22 \%$ shorter than that of BFB treatment $(P<0.05$; Figure 3). 


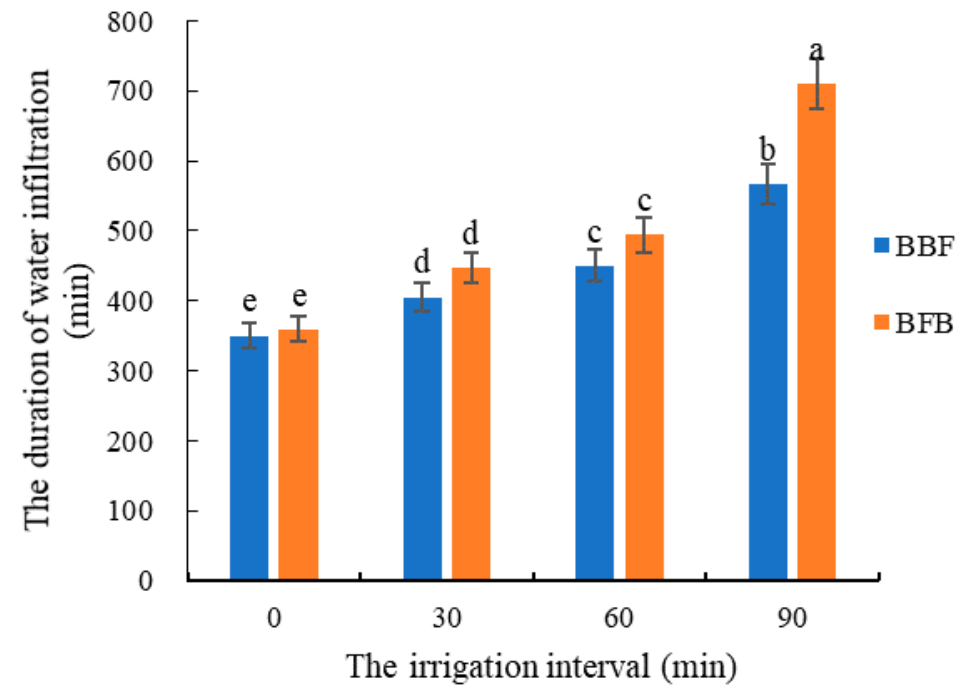

Figure 3. Effects of different irrigation treatments (BBF, brackish-brackish-fresh water; BFB, brackish-fresh-brackish water) on the duration of water infiltration in the silty loam. Different letters above columns indicate significant differences $(P<0.05)$.

Similar to the duration of infiltration, the mean soil water content under different treatments also increased with increasing irrigation interval (except for 60-min interval). Although, the differences were not significant $(P>0.05)$. Additionally, the soil water content of the BFB treatment was slightly, but not significantly, higher than that of the BBF treatment $(P>0.05)$.

\subsection{Effects of Irrigation with Brackish and Fresh Water on Salt Distribution}

Desalination occurred in the soil across depths of 0-32 cm under different treatments. The mean desalination rate significantly increased with increasing irrigation interval $(P<0.05)$. Especially for the BBF treatment at the 90-min interval, the mean desalination rate reached $49.07 \%$, which was 1.15 -fold over the same treatment at the 0-min interval (i.e., $42.51 \%$; Table 3).

Table 3. Mean desalination rate (\%) in the silty loam at depths of $0-32 \mathrm{~cm}$ under different irrigation treatments (BBF, brackish-brackish-fresh water; $\mathrm{BFB}$, brackish-fresh-brackish water).

\begin{tabular}{ccccc}
\hline \multirow{2}{*}{ Treatment } & Irrigation Interval (min) & \multicolumn{3}{c}{ Soil Depth (cm) } \\
\cline { 2 - 4 } & & $\mathbf{0 - 1 2}$ & $\mathbf{1 2 - 3 2}$ & $\mathbf{0 - 3 2}$ \\
\hline \multirow{3}{*}{ BBF } & 0 & $63.82 \pm 0.22 \mathrm{c}$ & $29.72 \pm 0.62 \mathrm{e}$ & $42.51 \pm 0.45 \mathrm{~d}$ \\
& 30 & $65.19 \pm 0.37 \mathrm{~b}$ & $33.01 \pm 0.56 \mathrm{~d}$ & $45.08 \pm 0.21 \mathrm{c}$ \\
& 60 & $63.95 \pm 0.46 \mathrm{c}$ & $36.33 \pm 0.23 \mathrm{c}$ & $46.69 \pm 0.32 \mathrm{~b}$ \\
& 90 & $66.98 \pm 0.25 \mathrm{a}$ & $38.32 \pm 0.34 \mathrm{~b}$ & $49.07 \pm 0.29 \mathrm{a}$ \\
\hline \multirow{3}{*}{ BFB } & 0 & $51.60 \pm 0.90 \mathrm{f}$ & $32.21 \pm 0.66 \mathrm{~d}$ & $39.48 \pm 0.71 \mathrm{e}$ \\
& 30 & $51.88 \pm 0.64 \mathrm{f}$ & $35.71 \pm 0.21 \mathrm{c}$ & $41.77 \pm 0.27 \mathrm{~d}$ \\
& 60 & $55.68 \pm 0.41 \mathrm{e}$ & $38.92 \pm 0.28 \mathrm{~b}$ & $45.21 \pm 0.31 \mathrm{c}$ \\
& 90 & $57.30 \pm 0.37 \mathrm{~d}$ & $40.13 \pm 0.27 \mathrm{a}$ & $46.57 \pm 0.26 \mathrm{~b}$ \\
\hline
\end{tabular}

Note: Different letters in the same column indicate significant differences $(P<0.05)$.

The mean desalination rate of BBF treatment was significantly higher than that of BFB treatment $(P$ $<0.05)$. However, changes in the mean desalination rate across different soil depths were inconsistent between these two treatments. At the $0-12 \mathrm{~cm}$ soil depth, the desalination rate of BBF treatment was higher than that of BFB treatment. For example, under irrigation at 30-min interval, the desalination rate of the BFB treatment $(51.88 \%)$ was 0.8 -fold over the BBF treatment $(65.19 \% ; P<0.05)$. However, the reverse was true at the $12-32 \mathrm{~cm}$ soil depth, with a higher soil desalination rate recorded for the 
BFB over BBF treatment. With irrigation applied at the 0 -min interval, the soil desalination rate of $\mathrm{BFB}$ treatment (32.21\%) showed an $8 \%$ increase over the BBF treatment $(29.72 \%, P<0.05$; Table 3$)$.

The mean SAR in the soil significantly decreased with an increasing interval of intermittent irrigation $(P<0.05)$. Taking the BBF treatment as an example, the mean SAR recorded at the 0-min irrigation interval was 23.41 , while a $21.04 \%$ decrease was observed under irrigation at the 90-min interval (Table 4).

Table 4. Mean sodium adsorption ratio in the silty loam at depths of 0-32 cm under different irrigation treatments (BBF, brackish-brackish-fresh water; $\mathrm{BFB}$, brackish-fresh-brackish water).

\begin{tabular}{ccccc}
\hline \multirow{2}{*}{ Treatment } & \multirow{2}{*}{ Irrigation Interval (min) } & \multicolumn{3}{c}{ Soil Depth (cm) } \\
\cline { 2 - 4 } & & $\mathbf{0 - 1 2}$ & $\mathbf{1 2 - 3 2}$ & $\mathbf{0 - 3 2}$ \\
\hline \multirow{3}{*}{ BBF } & 0 & $20.04 \pm 0.27 \mathrm{c}$ & $25.43 \pm 0.30 \mathrm{a}$ & $23.41 \pm 0.28 \mathrm{~b}$ \\
& 30 & $17.21 \pm 0.46 \mathrm{e}$ & $24.82 \pm 0.13 \mathrm{ab}$ & $21.97 \pm 0.24 \mathrm{c}$ \\
& 60 & $15.55 \pm 0.14 \mathrm{f}$ & $24.39 \pm 0.22 \mathrm{bc}$ & $21.08 \pm 0.09 \mathrm{~d}$ \\
& 90 & $13.10 \pm 0.58 \mathrm{~g}$ & $23.08 \pm 0.43 \mathrm{~d}$ & $19.34 \pm 0.48 \mathrm{e}$ \\
\hline \multirow{3}{*}{ BFB } & 0 & $23.19 \pm 0.38 \mathrm{a}$ & $24.95 \pm 0.53 \mathrm{ab}$ & $24.29 \pm 0.19 \mathrm{a}$ \\
& 30 & $23.70 \pm 0.59 \mathrm{a}$ & $23.83 \pm 0.12 \mathrm{c}$ & $23.78 \pm 0.15 \mathrm{ab}$ \\
& 60 & $21.72 \pm 0.34 \mathrm{~b}$ & $23.13 \pm 0.14 \mathrm{de}$ & $22.60 \pm 0.19 \mathrm{c}$ \\
& 90 & $18.26 \pm 0.26 \mathrm{~d}$ & $22.72 \pm 0.36 \mathrm{e}$ & $21.05 \pm 0.13 \mathrm{~d}$ \\
\hline
\end{tabular}

Note: Different letters in the same column indicate significant differences $(P<0.05)$.

The mean SAR of BBF treatment was significantly lower than that of BFB treatment $(P<0.05)$. The SAR at different soil depths showed inconsistent changes between BBF and BFB treatments. The BBF treatment resulted in lower soil SAR than did the BFB treatment at depths of 0-12 cm. For example, when irrigation was applied at the 60-min irrigation interval, the soil SAR of BBF treatment was 15.55; by comparison, an increase of $39.68 \%$ was observed under the BFB treatment $(P<0.05)$. However, at the 12-32 cm depth, the soil SAR of BBF treatment was higher than that of BFB treatment. Still, taking the irrigation interval of $60 \mathrm{~min}$ as an example, the soil SAR of BBF treatment was 24.39, with a 5.45\% decrease observed under the BFB treatment $(P<0.05$; Table 4$)$.

\section{Discussion}

The process of water and salt migration in the silty loam, during irrigation with brackish and fresh water, were analyzed, and the optimal strategy was identified, which supports the scientific and rational use of brackish water for farmland irrigation in the Yellow River Delta.

\subsection{Effects of Irrigation with Brackish and Fresh Water on Soil Water Content}

Our results showed that the duration of water infiltration in the silty loam increased with an increasing irrigation interval. Significant differences were observed in the duration of water infiltration between continuous (0-min interval) and intermittent (30-90 min intervals) irrigation with brackish and fresh water. During the intermittent irrigation process, we observed that the higher the irrigation frequency, the greater the initial soil water content. Higher initial water content of the soil can result in greater matric potential and hence lower soil water suction. Consequently, the matrix potential gradient generated becomes smaller and soil water migration is slowed down [23]. Moreover, the soil is subjected to alternate drying-wetting under intermittent irrigation, which changes the structural characters of surface soil and leads to the formation of a compact layer on it. A longer irrigation interval is conducive to the formation of the compact layer, and thus, extends the duration of water infiltration [24]. It was found by Wu and Wang [25] that, compared with continuous irrigation, intermittent irrigation, with brackish water $3 \mathrm{~g} / \mathrm{L}$ salinity, promotes water flow and reduces water infiltration in a sandy clay loam, at depths of 0 edu $\mathrm{cm}$. However, if soil salinity increases, the salt ions brought into the soil by brackish water may alter the structural characteristics of the soil and 
increase the soil macroporosity ( 3 and $5 \mathrm{~g} / \mathrm{L}$ salinity). As the compact soil layer contributes little to the reduction of infiltration, intermittent infiltration could increase the infiltration [26]. Therefore, these inconsistent results are attributed to different soil types and irrigation water quality [27].

In this study, we observed that the duration of water infiltration in the silty loam was shorter under the BBF, compared with the BFB treatment. First, the BBF may cause an increase in soil macroporosity, which could improve the soil permeability and lead to fast water infiltration [12]. Second, the BFB is conducive to the formation of effective pores, which could retain the infiltrated water in soil, rather than sustaining rapid water flow [28]. These may explain the difference in the duration of water infiltration between the two irrigation treatments with brackish and fresh water applied in different sequences.

However, the irrigation sequence of brackish and fresh water did not significantly affect the water content in the silty loam. The absence of significant differences in soil water content between these two irrigation sequences may be explained by the similar experimental conditions, including the volume and quality of irrigation water, the soil's initial water content, and soil type. In addition, evaporation in a short time $(20 \mathrm{~h})$ has little effect on water redistribution in the soil, which is insufficient to change soil water content.

\subsection{Effects of Irrigation with Brackish and Fresh Water on Soil Salt Content}

The distribution of soil salt is susceptible to various factors, such as soil water content, soil structure, and irrigation water quality [29]. Intermittent irrigation with brackish and fresh water can improve the soil water and salt environment, and promote crop growth. Herein, we found that the mean desalination rate in the silty loam was higher under intermittent irrigation at 30-, 60-, and 90-min intervals, compared with continuous irrigation, while the reverse was true for the mean soil SAR. Wu and Wang [25] also showed that intermittent irrigation can effectively reduce the occurrence of local accumulation of soil salt, thus ensuring the sustainable use of soil. Moreover, we found that the irrigation interval exhibited considerable effects on salt distribution in the silty loam; the higher desalination rate and lower SAR were recorded in the soil at a longer irrigation interval. On the one hand, as the frequency of irrigation increases, the frequency of salt migration, along with water flow, increases, leading to more sufficient leaching of salt in the upper soil layer. On the other hand, the effect of the irrigation interval on soil salt migration can be related to molecular diffusion, hydrodynamic dispersion, and negative adsorption under saturated-unsaturated flow conditions [23]. During intermittent irrigation, a longer time interval contributes to stronger unsaturated soil conditions, and the water in non-conductive pores can be transported by diffusion, thereby effectively removing the salt in the soil. Inversely, continuous irrigation receives continuous water supply, in which the saturated soil conditions can be enhanced with increasing duration of irrigation. Consequently, the migration of water in non-conductive pores may encounter difficulty, preventing the effective leaching of soil salt [23]. In summary, compared with continuous irrigation, intermittent irrigation with brackish and fresh water can achieve a higher desalination rate, and a longer irrigation interval is conducive to effective desalination of the soil tested in this study.

In this study, we found that BBF increased the mean desalination rate, while simultaneously lowering the mean SAR in the silty loam, compared with BFB. This may be due to the fact that after the first two irrigations with brackish water, the diffuse electric double layer is compressed toward the surface of the clay particles, which reduces the repulsive force between soil particles and enhances the flocculation of soil colloids, thereby forming soil aggregate structure and increasing soil water conductivity [30]. These conditions are conducive to salt leaching in the soil through the last irrigation with fresh water. Other studies have also demonstrated considerable effects of irrigation sequence on salt content in different soils. Su et al. [12] found that, in using the same volume and quality of irrigation water $(3 \mathrm{~g} / \mathrm{L}$ brackish water salinity and $0.5 \mathrm{~g} / \mathrm{L}$ fresh water salinity), the change of FBB to BFB increases the desalination rate in clay loam with secondary alkalization. In addition, Guan et al. [31] used brackish ( 2 and $4 \mathrm{~g} / \mathrm{L}$ salinity) and fresh water $(0 \mathrm{~g} / \mathrm{L}$ salinity) for alternating irrigation and found that BBF markedly reduced the salt content in a silty loam, at depths of $0-22.5 \mathrm{~cm}$, compared with BFB. 


\section{Conclusions}

Based on laboratory simulation experiments, this study revealed that the duration of water infiltration into the silty loam increased with the increasing irrigation interval. By comparing different irrigation sequences, we found a slight difference in the soil water content between BBF and BFB. At different depths in the soil, the desalination rate and sodium adsorption ratio exhibited inconsistent changes between the two treatments of alternating irrigation. Compared with continuous irrigation, intermittent irrigation with brackish and fresh water performed better in soil desalination. Taking into account soil salt content and SAR, brackish-brackish-fresh water irrigation at a longer time interval (e.g., 90 min between irrigations) is conducive to reducing soil salt accumulation in the surface soil in the study region.

Due to the limited study time and experimental conditions, the present study has been conducted in the laboratory and our conclusions have yet to be verified through field trials. Further, the effect of crops on soil water and salt migration should also be taken into consideration. When using brackish water for farmland irrigation, farmers should give consideration to the salinity of brackish water, the interval of intermittent irrigation, the sequence of alternating irrigation, the frequency of irrigation, and the salt tolerance of crops in different growth stages.

Author Contributions: Conceptualization, Z.Z. and J.Z.; methodology, J.Z.; software, J.Z.; validation, J.S., J.Z. and M.Y.; formal analysis, J.Z. and J.S.; investigation, J.Z. and M.Y.; resources, Z.Z.; data curation, M.Y.; writing —original draft preparation, J.Z.; writing—review and editing, J.Z. and J.S.; visualization, J.S. and Z.Z.; supervision, J.S.; project administration, J.Z.; funding acquisition, Z.Z.

Funding: This research was supported by National Natural Science Foundation of China [41771256, 41501309].

Acknowledgments: This research was supported by the Ecology laboratory of Ludong University and the Project of the Cultivation Plan of Superior Discipline Talent Teams of Universities in Shandong Province: "the Coastal Resources and Environment team for Blue-Yellow Area.

Conflicts of Interest: No potential conflict of interest was reported by the authors.

\section{References}

1. Xie, T.; Liu, X.H.; Sun, T. The effects of groundwater table and flood irrigation strategies on soil water and salt dynamics and reed water use in the Yellow River Delta, China. Ecol. Modell. 2011, 222, 241-252. [CrossRef]

2. Shah, S.H.H.; Vervoort, R.W.; Suweis, S.; Guswa, A.J.; Rinaldo, A.; Seatm, V.D.Z. Stochastic modeling of salt accumulation in the root zone due to capillary flux from brackish groundwater. Water Resour. Res. 2011, 47, 1995-2021. [CrossRef]

3. Kunhikrishnan, A.; Bolan, N.S.; Müller, K.; Laurenson, S.; Naidu, R.; Kim, W.I. The influence of wastewater irrigation on the transformation and bioavailability of heavy metal(loid)s in soil. Adv. Agron. 2012, 115, 215-297.

4. Tavakkoli, E.; Fatehi, F.; Coventry, S.; Rengasamy, P.; McDonald, G.K. Additive effects of $\mathrm{Na}^{+}$and $\mathrm{Cl}^{-}$ions on barley growth under salinity stress. J. Exp. Bot. 2011, 62, 2189-2203. [CrossRef]

5. Chen, W.I.; Jin, M.G.; Ferré, T.P.A.; Liu, Y.F.; Xian, Y.; Shan, T.R.; Ping, X. Spatial distribution of soil moisture, soil salinity, and root density beneath a cotton field under mulched drip irrigation with brackish and fresh water. Field Crops Res. 2018, 215, 207-221. [CrossRef]

6. Minhas, P.S. Saline water management for irrigation in India. Agric. Water Manage. 1996, 30, 1-24. [CrossRef]

7. Singh, R. Simulations on direct and cyclic use of saline waters for sustaining cotton-wheat in a semi-arid area of north-west India. Agric. Water Manage. 2004, 66, 1-162. [CrossRef]

8. Verma, A.K.; Gupta, S.K.; Isaac, R.K. Use of saline water for irrigation in monsoon climate and deep water table regions: Simulation modeling with SWAP. Agric. Water Manage. 2012, 115, 186-193. [CrossRef]

9. Kahlon, U.Z.; Murtaza, G.; Ghafoor, A. Amelioration of saline-sodic soil with amendments using brackish water, canal water and their combination. Int. J. Agric. Biol. 2012, 14, 38-46.

10. Yazar, A.; Incekaya, Ç; Sezen, S.M.; Jacobsen, S.E. Saline water irrigation of quinoa (Chenopodium quinoa) under Mediterranean conditions. Crop Pasture Sci. 2015, 66, 993-1002. [CrossRef] 
11. Xue, J.; Qang, Q.J.; Wang, Y.J. Soil infiltration properties with slight saline water intermittent application. Trans. Chin. Soc. Agric. Eng. 2009, 25, 14-19, (In Chinese with an English Abstract).

12. Su, Y.; Wang, Q.J.; Ye, H.Y.; Shi, X.N. Research of soil water and salt transport feature for alternative irrigation of fresh and saline water. J. Irrig. Drain. Eng. 2005, 24, 50-53, (In Chinese with an English Abstract).

13. Guan, B.; Yu, J.B.; Hou, A.X.; Han, G.X.; Wang, G.M.; Qu, F.Z.; Xia, J.B.; Wang, X.H. The ecological adaptability of Phragmites australis to interactive effects of water level and salt stress in the Yellow River Delta. Aquat. Ecol. 2017, 51, 107-116. [CrossRef]

14. Luo, X.X.; Liu, G.C.; Xia, Y.; Chen, L.; Jiang, Z.X.; Zheng, H.; Wang, Z.Y. Use of biochar-compost to improve properties and productivity of the degraded coastal soil in the Yellow River Delta, China. J. Soils Sediments 2017, 17, 780-789. [CrossRef]

15. Liu, S.; Tang, Z.H.; Gao, M.S.; Hou, G.H. Evolutionary process of saline-water intrusion in Holocene and Late Pleistocene groundwater in southern Laizhou Bay. Sci. Total Environ. 2017, 607-608, 586-599. [CrossRef]

16. Xue, Y.Q.; Wu, J.C.; Ye, S.J.; Zhang, Y.X. Hydrogeological and hydrogeochemical studies for salt water intrusion on the south coast of Laizhou Bay, China. Ground Water 2010, 38, 38-45. [CrossRef]

17. Waller, P.; Yitayew, M. Irrigation and Drainage Engineering; Springer International Publishing: Tucson, AZ, USA, 2016.

18. Zhao, Y.N.; Wang, Y.K.; Ma, L.H.; Lin, P.H.; Duan, X.S. Investigation on undisturbed soil water redistribution under drip irrigation. J. Irrig. Drain. Eng. 2010, 29, 44-49, (In Chinese with an English Abstract).

19. Sun, J.N.; He, F.H.; Zhang, Z.H.; Shao, H.B.; Pan, Y.H.; Yang, R.Y.; Li, W.X.; Li, P.; Zheng, M.Z. Analysis of saline groundwater infiltration into two loam soils. Land Degrad. Dev. 2018, 29, 3795-3802. [CrossRef]

20. Chen, L.J.; Feng, Q.; Li, F.R.; Li, C.S. Simulation of soil water and salt transfer under mulched furrow irrigation with saline water. Geoderma 2015, 241-242, 87-96. [CrossRef]

21. Yan, K.; Xu, H.L.; Zhao, S.J.; Shan, J.J.; Chen, X.B. Saline soil desalination by honeysuckle (Lonicera japonica Thunb.) depends on salt resistance mechanism. Ecol. Eng. 2016, 88, 226-231. [CrossRef]

22. Sposito, G.; White, R.E.; Darrah, P.R.; Jury, W.A. A transfer function model of solute transport through soil: 3. The convection-dispersion equation. Water Resour. Res. 1986, 22, 255-262. [CrossRef]

23. Darvishan, A.K.; Banasik, K.; Sadeghi, S.H.; Gholami, L.; Hejduk, L. Effects of rain intensity and initial soil moisture on hydrological responses in laboratory conditions. Int. Agrophys. 2015, 29, 165-173. [CrossRef]

24. Heydari, N.; Gupta, A.D.; Loof, R. Salinity and sodicity influences on infiltration during surge flow irrigation. Irrig. Sci. 2001, 20, 165-173.

25. Wu, Z.D.; Wang, Q.J. Effect of saline water surge flow border irrigation on soli water salt distribution. Trans. Chin. Soc. Agric. Mach. 2010, 41, 53-58, (In Chinese with an English Abstract).

26. Yan, Y.L.; Bi, Y.J.; Guo, X.H.; Xiang, X.H.; Ma, J.J.; Liu, J.Y. Analysis of soil water and salt distribution of saline water intermittent water supply mode. Water Saving Irrig. 2015, 6, 42-46, (In Chinese with an English Abstract).

27. Bi, Y.J.; Wang, Q.J.; Xue, J. Infiltration characteristic contrast analysis of fresh water and saline water. Trans. Chin. Soc. Agric. Mach. 2010, 41, 70-75, (In Chinese with an English Abstract).

28. Beesley, L.; Eduardo, M.J.; Clemente, R.; Lepp, N.; Dickinson, N. Mobility of arsenic, cadmium and zinc in a multi-element contaminated soil profile assessed by in-situ soil pore water sampling, column leaching and sequential extraction. Environ. Pollut. 2010, 158, 155-160. [CrossRef]

29. Akramkhanov, A.; Martius, C.; Park, S.J.; Hendrickx, J.M.H. Environmental factors of spatial distribution of soil salinity on flat irrigated terrain. Geoderma 2011, 16, 1-62. [CrossRef]

30. Gawad, G.A.; Arslan, A.; Gaihbe, A.; Kadouri, F. The effects of saline irrigation water management and salt tolerant tomato varieties on sustainable production of tomato in Syria (1999-2002). Agric. Water Manage. 2005, 78, 1-53.

31. Guan, X.Y.; Yang, P.L.; Lv, Y. Laboratory experiment on the redistribution of soil salinity under saline and fresh water alternate irrigation. Trans. Chin. Soc. Agric. Eng. 2007, 23, 88-91. (In Chinese with an English Abstract)

(C) 2019 by the authors. Licensee MDPI, Basel, Switzerland. This article is an open access article distributed under the terms and conditions of the Creative Commons Attribution (CC BY) license (http://creativecommons.org/licenses/by/4.0/). 